\title{
DEEP NEURAL NETWORK TOOL CHATTER MODEL FOR ALUMINUM SURFACE MILLING USING ACOUSTIC EMMISION SENSOR M. Abul Hasan ${ }^{1}$, Muhamad-Husaini Abu-Bakar ${ }^{1 *}$, Rizal Razuwan ${ }^{1}$, Zainal Nazri ${ }^{1}$
}

\author{
${ }^{1}$ System Engineering and Energy Laboratory, \\ Universiti Kuala Lumpur Malaysian Spanish Institute, \\ *Email: muhamadhusaini@unikl.edu.my \\ Phone: +6044035199; Fax: +6044035201
}

\begin{abstract}
Chatter is a self-excited vibration in any machining processes which contributes to the system instability due to resonance and resulting in an inaccuracy in machining product. Due to demand for a high precision product, industries are nowadays moving towards implementing a tool monitoring system as a feedback. Currently, an electromagnetic sensor was used to detect chatter in tools, but this sensor introduces a drawback such as bulky in size, sensitive to noise and not suitable to be implemented in the small machining center. This paper aims to propose a chatter identification model for face milling tool based on acoustic emission data for tool monitoring system. Acoustic emission data is collected at four level of cutting depth in milling with linear tool path movement on aluminum T6 6061 materials. The Deep Neural Network (DNN) model was developed using multiple deep-learning frameworks for the chatter detection system. This model approach shows a good agreement with experimental data with $4 \%$ error. As a conclusion, the DNN chatter identification model was successfully developed for the aluminum milling process applications. This finding is essential for anomaly detection during machining process and able to suggest for a better machining parameter for the aluminum machining process.
\end{abstract}

Keywords: Tool Chatter, Deep Neural Network, Acoustic Emission, Anomaly detection.

\section{INTRODUCTION}

Chatter identification has been available in many countries especially in the first-class country. There are many applications of chatter identification which have been studied and developed by many researchers such as detect breakages, detect vibration, and monitoring system. In addition, chatter identification also applicable in machine vision, tool toughness, dimensional accuracy, and surface roughness application. Chatter is a self-excited vibration in any machining processes which contribute to the system instability due to resonance and resulting in any damage to the workpiece also machine tool [1]. Thus, the machining process today's need the chatter identification system.

Nowadays, manufacturing enterprises are moving in line with Industry 4.0 which turning towards full automation, reliable, online, and robust monitoring system for more productivity, quality, precision, and reduced costs [2]. In practice, tool monitoring system utilizes a chatter identification result to determine a degree of vibration in the machining process. Tool monitoring system is the system which manages, monitor and analyzes the process of machining process for detecting the defect in the process or tools [3]. Indeed, in maintaining high quality in automated and 
un-manned manufacturing, the tool integrity must be maintained, tool condition monitoring is required [4].

Chatter identification was known as fundamental techniques in tool monitoring system. Many types of sensor which emitted vibration input data such as an accelerometer, electromagnetic and ultrasonic sensors. Numbers of researcher suggest using an electromagnetic sensor to detect chatter in a tool [5], but this kind of sensors introduce a drawback such as bulky in size, sensitive to noise and not suitable to implement in a small machining center.

In that case, the spectral domain obtained from Fourier analysis was the perfect alternative used to extract frequency-domain features of measured vibration signals from acoustic emission sensors [6]. In the last decade, NNs have been applied to monitor machining processing, including turning, milling and grinding machines [7]. Different from traditional methods, deep learning is a new machine learning methods, which has the great capacity to automatically learn the valuable features and inference from the data [8].

Hence, the aim of this research is to develop a chatter identification model for tool monitoring system using Deep Neural Network (DNN) model which using acoustic emission input data. The proposed model was predicted to gives an accurate solution of chatter identification system. This project goal was to develop an experimental setup for proposed model in the milling process which divided into several phases.

\section{METHODOLOGY}

\section{Experimental Setup}

Experimental setup of this project has been designed and set-up for tool monitoring system. However, identification of component parameters needs verification before proceeding to the experimental setup. Firstly, the elements in experimental setups must be accurate and precise for monitoring the chatter. Therefore, the calibrations process must be conducted before further experimenting to make sure the components are in good condition for monitoring the tools wear and specimen surface roughness.

Table 1. The component of experimental

\begin{tabular}{|c|c|c|}
\hline No & Component & Type \\
\hline 1 & $\begin{array}{c}\text { CNC Milling } \\
\text { Machine }\end{array}$ & Fagor C355 \\
\hline 2 & Flat End Mill & $16 \mathrm{~mm}$ 2 Flutes (HSS) \\
\hline 3 & Aluminium Block & $\begin{array}{c}100 \mathrm{~mm} \text { x 100 mm x 25 } \\
\mathrm{mm}\end{array}$ \\
\hline 4 & Computer Monitor & HP EliteDisplay E201 \\
\hline 5 & Preamplifier & Mistras Preamplifier \\
\hline 6 & AE System & Mistras Micro-ii Digital \\
\hline 7 & AE Sensor & $\begin{array}{c}\text { WD - 100-900 KHZ } \\
\text { Wideband Differential AE } \\
\text { Sensor }\end{array}$ \\
\hline
\end{tabular}




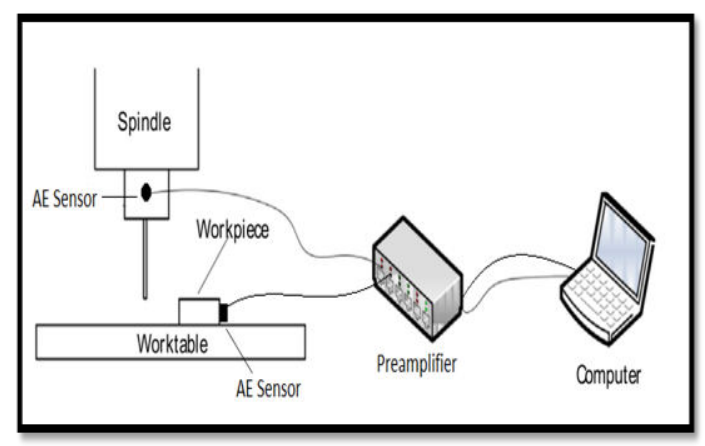

(a)

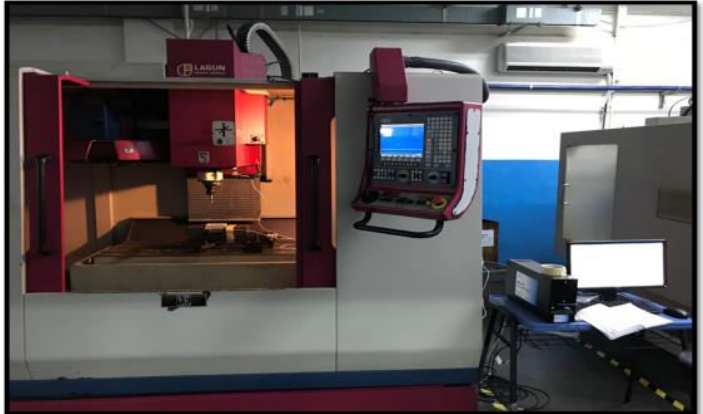

(b)

Figure 1. (a) Schematic diagram of experimental setup (b) Picture of experimental setup

Next, the milling tests were performed with a Fagor C355 CNC milling machine as shown in Figure 1 (a) and (b). The specimen of aluminum T6 6061 material within a specific size was clamped on the work table and High Speed Steel (HSS) end mill cutter with two flutes and diameter $16 \mathrm{~mm}$ was used. The measurements were conducted using Mistras Micro-ii Digital system combined with its software, AEWin. Acoustic emission sensors were mounted on the spindle housing to measure the vibration signals during the milling process on the work table which the specimen was clamped to record the vibration signals during the machining processes. The integrated acoustic emission sensor process and receive the vibration signals and convert it's into data.

Since the occurrence of chatters was directly correlated with the depth of the cutting, each experiment have been conducted at a constant spindle speed of $2000 \mathrm{r} / \mathrm{min}$, a feed rate of $747 \mathrm{~mm} / \mathrm{min}$, and with a different depth of the cutting at $0 \mathrm{~mm}, 1.0 \mathrm{~mm}$, $3.0 \mathrm{~mm}$ and $5.0 \mathrm{~mm}$, respectively. All the experiments were slotting without cutting fluids. The parameters for chatter identification was classified into steady, chatter level 1, chatter level 2 and chatter level 3 as shown in Table 2.

Table 2. The parameters for chatter identification system

\begin{tabular}{|c|c|c|c|c|}
\hline $\begin{array}{c}\text { Cutting } \\
\text { Condition }\end{array}$ & $\begin{array}{c}\text { Depth of a cut } \\
(\mathrm{mm})\end{array}$ & $\begin{array}{c}\text { Spindle } \\
\text { Speed } \\
(\mathrm{rpm})\end{array}$ & $\begin{array}{c}\text { Feedrate } \\
(\mathrm{mm} / \mathrm{min})\end{array}$ & Remarks \\
\hline Steady State & 0 & 2000 & 747 & Without coolant fluid \\
\hline Chatter Level 1 & 1 & $2000)$ & 747 & Without coolant fluid \\
\hline Chatter Level 2 & 3 & 2000 & 747 & Without coolant fluid \\
\hline Chatter Level 3 & 5 & 2000 & 747 & Without coolant fluid \\
\hline
\end{tabular}




\section{Data Analysis}

The signal data that has been emitted by AE sensors was transmitted through preamplifier for making a signal fit for the next experimental stage in the signal chains and performing a filtering process for an unwanted signal. This approach was performed due to a noise in the system and was overcome by adding a preamplifier for minimizing a noise in the system compared to raw signals. The tuned signals have been transmitted to the computer database for the data analysis procedures.

The acquisition of the data between steady and chatter condition that was acquired has been transformed and prepared for time-frequency data. The data preparation, transformation, and visualization were produced using multiple opensource tools which specialized in machine learning platforms such as Rstudio desktop version '1.0.153' [9], SAS University Edition Studio, Orange [10], and Spyder Python integrated development environment (IDE).Furthermore, the proposed model for chatter identification was also developed using tool mentions before and the model was trained and evaluated with the experimental data.

\section{Chatter Identification Model}

The tools used for developing the model was a GPU-accelerated and thus, reducing the time need for computing the developed model. The requirements for using multiples deep-learning frameworks such as Keras [11], TensorFlow [12], and Microsoft Cognitive Toolkit (CNTK) [13] was installing all dependencies and set-up our model environment. The advantages of using multiple deep-learning frameworks were less computing time, customized model, a high-level abstraction layer, and fast prototyping. The DNN model was developed by using Long Short Term Memory (LSTM) network from Keras model which can outperform the state-of-the-art anomaly detection algorithms on time-series data. Figure 2 shows the basic LSTM network illustration.

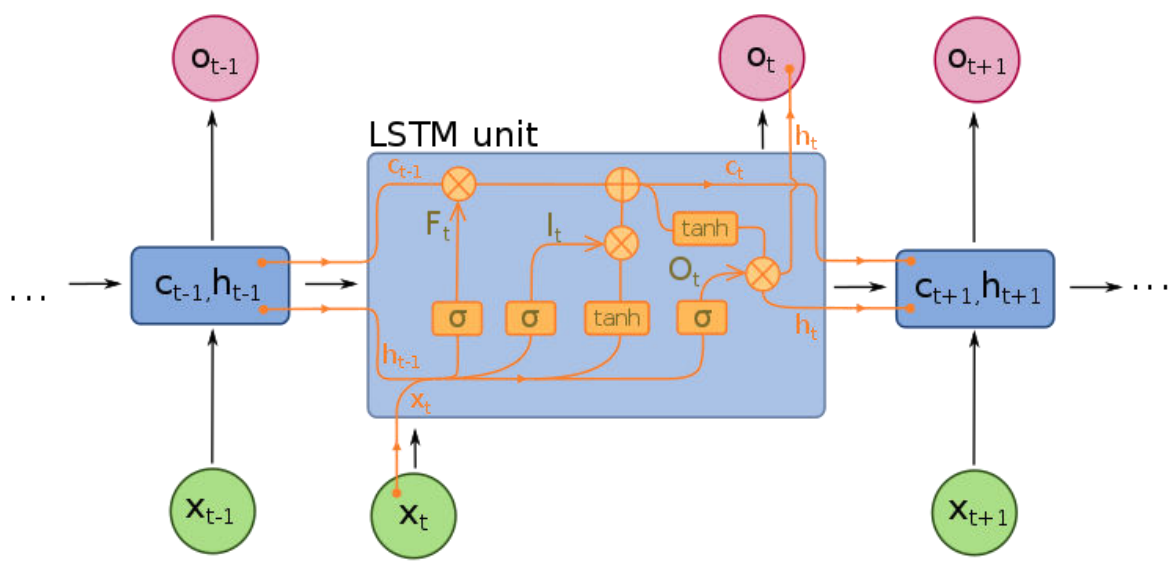

Figure 2. Basic example of LSTM network 


\section{RESULTS AND DISCUSSION}

\section{Analysis of Chatter Condition}

Figure 3 (a) and (b) shows the visualization and analysis of chatter condition from the first stage into the second stage using chatter identification system that was developed. The process of identification was implemented during machining process on CNC milling machine. The result shows the frequency of specimen cutting condition against time taken for different stages.

As shown below for specimen condition in Figure 3(a), there was an arising chatter that was caught by the chatter identification system which starts from steady state and suddenly arose to a peak point during the machining process. Based on this result, this shows that the chatter can be identified using the developed model of chatter identification system. Moreover, in Figure 3(b) the pattern of chatter condition was different than Figure 3(a) which was obviously showing the differences in amplitude of the chatter frequency. This was caused by the difference in cutting depth which clearly proved that the increase of cutting depth influence the peak of anomaly chatter and tool wear rate.

In the middle of chatter pattern in Figure 3(b), showed that the amplitude starts to rise back after a colossal drop and then suddenly drop before begin to increase in the late time of the second stage. These anomalies were identified and visualized using the developed chatter identification system for tool monitoring system which can be used for the system feedback to ensure high precision product.

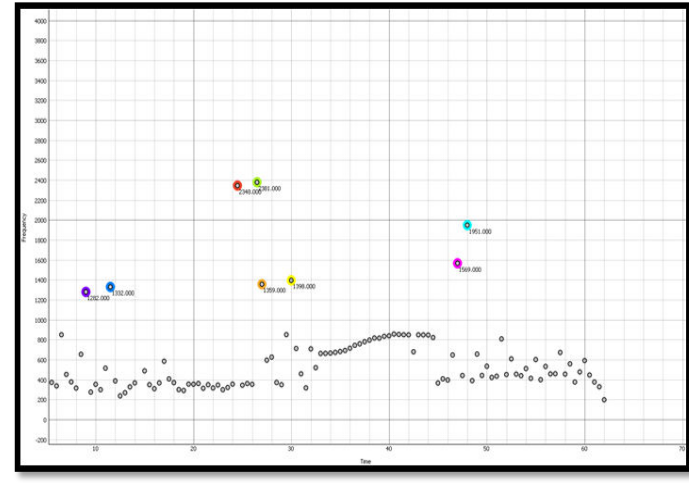

(a)

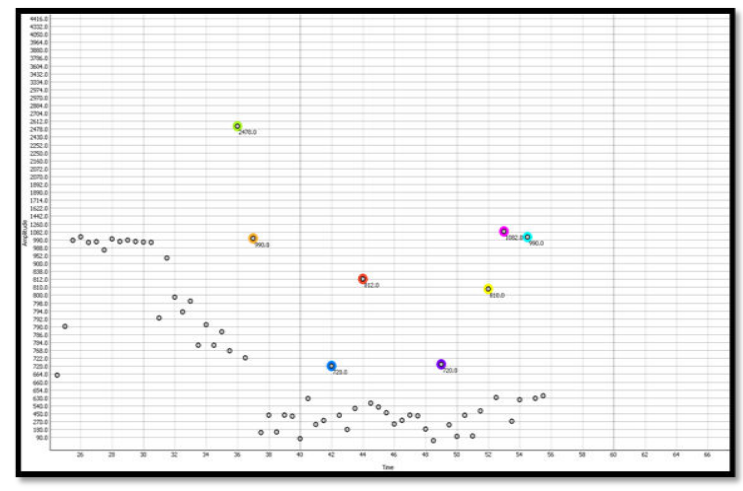

(b)

Figure 3. (a) First stage of chatter condition (b) Second stage of chatter condition 


\section{Analysis of Steady Condition}

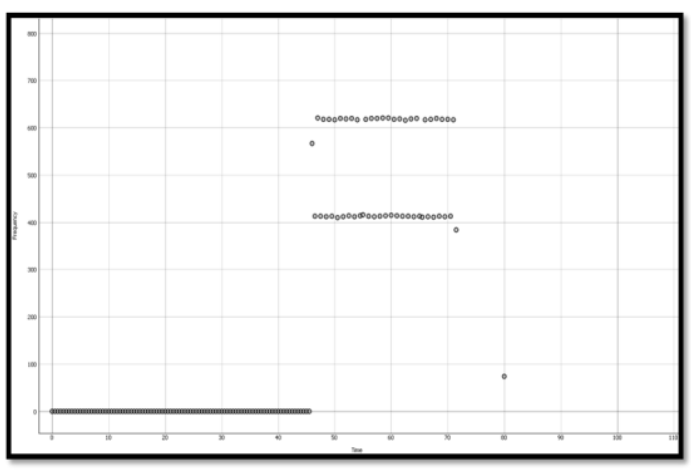

(a)

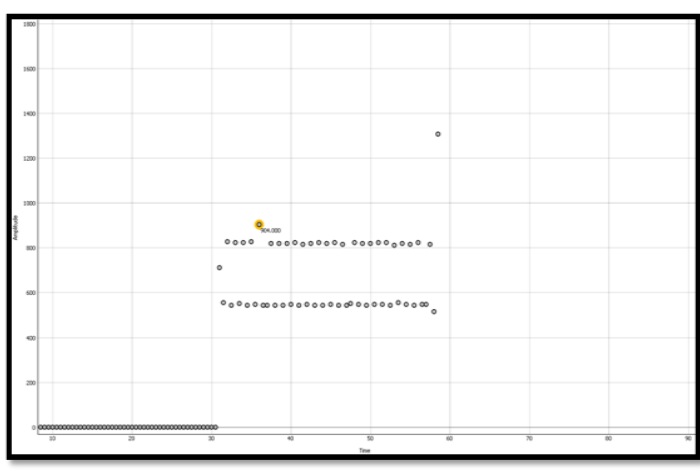

(b)

Figure 4. (a) First stage of steady condition (b) Second stage of steady condition

Based on these result in Figure 4(a) and (b), there were only minor anomalies detected during steady condition which caused less tool wear condition during the machining process. Figure 3 (a) shows no arising chatter identified by the chatter identification system and reveal that the machining process was in steady state and minor anomalies. The maximum frequency detected in the first stage was $876 \mathrm{~Hz}$ which is less than the second stage maximum frequency, $904 \mathrm{~Hz}$.

\section{Comparison of chatter and steady conditions}

From the previous study, it was explained that the most frequency components directly in the range of $500 \mathrm{~Hz}$ to $3000 \mathrm{~Hz}$ [14]. Then, the distribution of the frequency starts to concentrate on a range of chatter frequencies condition. Based on the result in Figure 5, the most of the frequencies have been detected in the range 720-2478 Hz. Nonetheless, the distribution of frequency components have been not concentrated in range the chatter frequencies, but it was freely chattering identification regarding after tool was passing through and contacted on the specimen. The proposed method used with Orange [10] was not precisely same output as Fourier spectra but this method significantly improves the accuracy of tool monitoring system by gaining $12.4 \%$ from previous research.

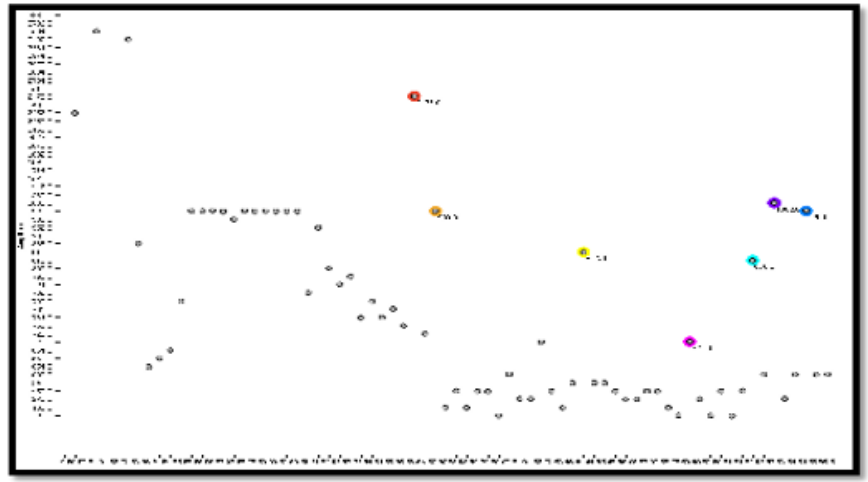

Figure 5. Chatter identification from experimental data 


\section{CONCLUSION}

Based on the resuts, the proposed model of chatter identification system which was developed with DNN model was able to detect the chatter in the aluminum surface milling process using AE sensors. Besides that, this model was proved in this experimental more reliable and robust for more productivity, quality, precision, and eventually reducing the cost. This model also able to define the symptom and phenomenon of chatter occurrence in both time and frequency domain. Lastly, the advent of Artificial Intelligence (AI) proves that it can solve a complex problem and can be used for better human futures.

\section{REFERENCES}

[1] Wan, S., Li, X., Chen, W., \& Hong, J. (2018). Investigation on milling chatter identification at early stage with variance ratio and Hilbert-Huang transform. International Journal of Advanced Manufacturing Technology, 95(9-12), 35633573. https://doi.org/10.1007/s00170-017-1410-y

[2] Wan, S., Li, X., Chen, W., \& Hong, J. (2018). Investigation on milling chatter identification at early stage with variance ratio and Hilbert-Huang transform. International Journal of Advanced Manufacturing Technology, 95(9-12), 35633573. https://doi.org/10.1007/s00170-017-1410-y

[3] Abellan Nebot J and Romero Subiro' n F (2010) A review of machining monitoring systems based on artificial intelli- gence process models. The International Journal of Advanced Manufacturing Technology 47: 237-257.

[4]Ratava, J., Lohtander, M., \& Varis, J. (2017). Tool condition monitoring in interrupted cutting with acceleration sensors. Robotics and Computer-Integrated Manufacturing, 47(November), 70-75. https://doi.org/10.1016/j.rcim.2016.11.008

[5] Ahrens, M., Dagen, M., Denkena, B., \& Ortmaier, T. (2016). An Active Damping Method for Chatter Vibration in Plunge Grinding Using Electromagnetic Actuators. Procedia CIRP, 46, 197-200. https://doi.org/10.1016/j.procir.2016.03.200

[6] Samanta B, Al-Balushi KR and Al-Araimi SA (2006) Artificial neural networks and genetic algorithm for bearing fault detection. Soft Computing - A Fusion of Foundations, Methodologies and Applications 10: 264-271.

[7] Yao Z, Mei D and Chen Z (2010) On-line chatter detection and identification based on wavelet and support vector machine. Journal of Materials Processing Technology 210: 713-719.

[8] Wan, S., Li, X., Chen, W., \& Hong, J. (2018). Investigation on milling chatter identification at early stage with variance ratio and Hilbert-Huang 
transform.International Journal of Advanced Manufacturing Technology, 95(9-12), 3563-3573. https://doi.org/10.1007/s00170-017-1410-y

[9] RStudio Team (2015). RStudio: Integrated Development for R. RStudio, Inc., Boston, MA URL http://www.rstudio.com/

[10] Demsar J, Curk T, Erjavec A, Gorup C, Hocevar T, Milutinovic M, Mozina M, Polajnar M, Toplak M, Staric A, Stajdohar M, Umek L, Zagar L, Zbontar J, Zitnik M, Zupan B (2013) Orange: Data Mining Toolbox in Python. Journal of Machine Learning Research 14(Aug):2349-2353.

[11] Chollet, Franc sois. Keras. https://github.com/fchollet/keras, 2015.

[12] TensorFlow: Large-scale machine learning on heterogeneous systems, 2015, Software available from tensorflow.org.

[13] Frank Seide and Amit Agarwal. 2016. CNTK: Microsoft's Open-Source DeepLearning Toolkit. In Proceedings of the 22nd ACM SIGKDD International Conference on Knowledge Discovery and Data Mining (KDD '16). ACM, New York, NY, USA, 2135-2135. DOI: https://doi.org/10.1145/2939672.2945397

[14] Cao, H., Zhou, K., \& Chen, X. (2015). Chatter identification in end milling process based on EEMD and nonlinear dimensionless indicators. International Journal of Machine Tools and Manufacture, 92, 52-59. 